\title{
E-Cadherin and Cadherin-Associated Cytoplasmic Proteins Are Expressed in Murine Mast Cells
}

\author{
Tatsuya Tegoshi, Minoru Nishida, Kenji Ishiwata, Takahiko Kobayashi, \\ Fukumi Uchiyama, Kazuki Nabeshima, Yukifumi Nawa, and Naoki Arizono
}

Department of Medical Zoology (TT, MN, NA), Kyoto Prefectural University of Medicine, Kyoto; and Department of Parasitology (KI, TK, FU, YN), and Second Department of Pathology (KN), Miyazaki Medical College, Miyazaki, Japan

\begin{abstract}
SUMMARY: Cadherins, calcium-dependent cell adhesion molecules, play crucial roles, not only in the maintenance of tissue integrity, but also in the regulation of many aspects of cell behavior. We investigated the expression of "classic" $\mathrm{E}-$-, $\mathrm{N}$ - and $\mathrm{P}$-cadherins in bone marrow-derived cultured mast cells (BMMC) and peritoneal mast cells (PMC) from mice. Flow cytometric analysis and immunocytochemical staining indicated that E-cadherin was expressed on the cell surface of BMMC and also at lower levels on PMC. N-cadherin was also expressed on the surface of BMMC, but not of PMC, whereas P-cadherin expression was seen in neither cell type. Significant expression of $\mathrm{E}$ - and N-cadherin mRNA was observed in BMMC by reverse transcriptase-polymerase chain reaction (RT-PCR), but PMC expressed only E-cadherin mRNA. Western blotting analysis indicated expression of $\alpha$ - and $\beta$-catenins and p120-catenin (or p120 cas) in BMMC, whereas PMC showed less intense expression of $\alpha$ - and $\beta$-catenins with high levels of p120 expression. Analyses of $\beta$-catenin or E-cadherin immunoprecipitates from BMMC lysate revealed that $\alpha$-catenin, $\beta$-catenin, and E-cadherin were co-precipitated, suggesting that $\mathrm{E}$-cadherin and catenins form a complex in mast cells. Addition of a blocking antibody of homophilic E-cadherin interactions, or a synthetic E-cadherin-binding decapeptide containing the histidine-alanine-valine (HAV) sequence in methylcellulose cultures of gut intraepithelial mononuclear cells or BMMC, significantly suppressed the clonal growth of mast cells. Furthermore, the blocking antibody or synthetic decapeptide significantly suppressed BMMC adhesion to E-cadherin-expressing F9 cell monolayers. These results indicated that E-cadherin and associated cytoplasmic proteins in mast cells might be involved in the regulation of certain stages of mast cell differentiation and cell-cell interactions. (Lab Invest 2000, 80:1571-1581).
\end{abstract}

\begin{abstract}
$M$ ast cells localize in various tissues through adhesive interactions with tissue components. Mast cells attach to extracellular matrix molecules such as laminin, vitronectin, and fibronectin spontaneously or after lgE-mediated activation or treatment with phorbol myristate acetate (Bianchine et al, 1992; Thompson et al, 1989; Thompson et al, 1990). Several integrins, receptors for these molecules, are expressed on mast cells: $\alpha_{4} \beta_{1}, \alpha_{5} \beta_{1}$, and $\alpha_{6} \beta_{1}$ in murine bone marrow-derived cultured mast cells (BMMC) and peritoneal mast cells (PMC), $\alpha_{4}, \alpha_{5}$, and $\beta_{3}$ in a rat basophilic leukemia cell line (RBL-2H3), and $\alpha_{4} \beta_{1}$, $\alpha_{5} \beta_{1}$, and $\alpha_{\mathrm{v}} \beta_{3}$ in a human mast cell line (HMC-1) (Ducharme and Weis, 1992; Gurish et al, 1992; Palecanda et al, 1997). In certain conditions, such as type I asthma, allergic rhinitis, or intestinal nematode infections, mast cells are occasionally found in the respi-
\end{abstract}

\section{Received July 21, 2000.}

This work was supported by a grant-in-aid for exploratory research (No. 10877045) and scientific research (C) (No. 12670237) from the Ministry of Education, Science, Sports and Culture of Japan, and by grants from the Toray Research Institute and the Dr. Shimizu Foundation for the Promotion of Immunology.

Address reprint requests to: Dr. Naoki Arizono, Department of Medical Zoology, Kyoto Prefectural University of Medicine, KawaramachiHirokoji, Kyoto, 602-8566, Japan. Fax: 8175251 5328; E-mail: arizonon@basic.kpu-m.ac.jp ratory or gut epithelium, but the adhesion molecules involved in the localization or invasion of mast cells in the epithelium have not been fully elucidated. Adhesive interactions between epithelial cells and intraepithelial lymphocytes, or between keratinocytes and epidermal Langerhans cells, were reported to be mediated, at least in part, by E-cadherin and $\alpha^{\mathrm{E}} \beta_{7}$ integrin (Cepek et al, 1994; Tang et al, 1993). Because murine $\mathrm{BMMC}$ were reported to express $\alpha^{\mathrm{E}}$ integrin in the presence of TGF- $\beta$ or by cross-linking of FceRI (Smith et al, 1994), heterophilic interactions between integrins and E-cadherin might be involved in homing of mast cells to intraepithelial sites.

Cadherins are structurally and functionally related transmembrane glycoproteins that mediate homophilic, calcium-dependent cell-cell adhesion, development, and morphogenesis (Takeichi, 1991). Various types of cadherins have been identified: E-cadherin is expressed on most epithelia and some carcinoma cells of epithelial origin, $\mathrm{N}$-cadherin in nervous tissues, and P-cadherin in the placenta. Dysfunction of cadherin has been implicated in the invasiveness and carcinogenesis of tumor cells (Shimoyama et al, 1992). E- and $\mathrm{N}$-cadherins were found to be expressed, not only on epithelial cells or neural tissues, but also on bone marrow-derived cells such as Langerhans dendritic cells, erythropoietic cells of defined maturational stages, and certain $\mathrm{T}$ cells and $\mathrm{T}$ 
cell lymphoma cell lines (Aiba et al, 1995; Armeanu et al, 1995; Buhring et al, 1996; Caux et al, 1996; Kawamura et al, 1998; Munro et al, 1996; Tsutsui et al, 1996). Expression of cadherins in these cells was implicated in cadherin-mediated interactions with epithelial or stromal cells, but it was also supposed to be involved in the differentiation or ontogeny of these cells. However, expression of cadherins on mast cells has not been elucidated.

In the present study, we examined expression of cadherins and cadherin-associated cytoplasmic proteins in mast cells. The results of the present study indicated that murine BMMC and PMC expressed E-cadherin as well as $\alpha$ - and $\beta$-catenin and p120. Functional blocking studies of E-cadherin also indicated that the process of mast cell differentiation and/or proliferation, and cell-cell interactions could be regulated by signals through $\mathrm{E}$-cadherin.

\section{Results}

\section{Expression of Cadherins on Mast Cells}

Classic E-, N-, and P-cadherin expression on BMMC or PMC was studied by flow cytometry using monoclonal antibodies (mAbs) that recognize the extracellular domain of each cadherin. The majority of BMMC obtained 4 weeks after the start of bone marrow cell culture expressed c-kit receptors (Fig. 1), and metachromatic granules were detected by toluidine blue-O staining. Both BMMC and PMC revealed significant expression of E-cadherin, irrespective of the presence or absence of blocking reagent for Fc receptors on mast cells (Fig. 1). N-cadherin expression was observed on BMMC, but not on PMC, and P-cadherin was seen in neither cell type (Fig. 1).

Immunostaining of cadherins on cytospin preparations of BMMC and PMC showed similar results to FACS analysis. E-cadherin was localized along the cell membranes of most BMMC, as well as those of PMC with weak immunoreactivity in the cytoplasm (Fig. 2, A and D). $\mathrm{N}$-cadherin immunoreactivity was found in BMMC but not in PMC (Fig. 2, B and E). P-cadherin was undetectable in both cell types (not shown).

Expression of E-cadherin was also examined in paraffin-embedded sections. Immunohistochemistry using anti-E-cadherin, clone 32, which recognizes the intracellular domain of E-cadherin, showed immunoreactivity on the cell membranes of mast cells as well as epithelial cells (Fig. 3). Anti-E-cadherin mAb (ECCD)-2 did not react to cell membranes of either mast cells or tongue squamous epithelial cells in paraffin-embedded sections probably because of the loss of antigenicity.

$\mathrm{E}$ - and $\mathrm{N}$-cadherin gene expression in mast cells was examined by reverse transcriptase-polymerase chain reaction (RT-PCR). Both $B M M C$ and $P M C$ showed E-cadherin mRNA expression (Fig. 4, lanes 3 and 4, respectively), whereas expression of $\mathrm{N}$-cadherin was observed only in BMMC (Fig. 4, lanes 7 and 8).
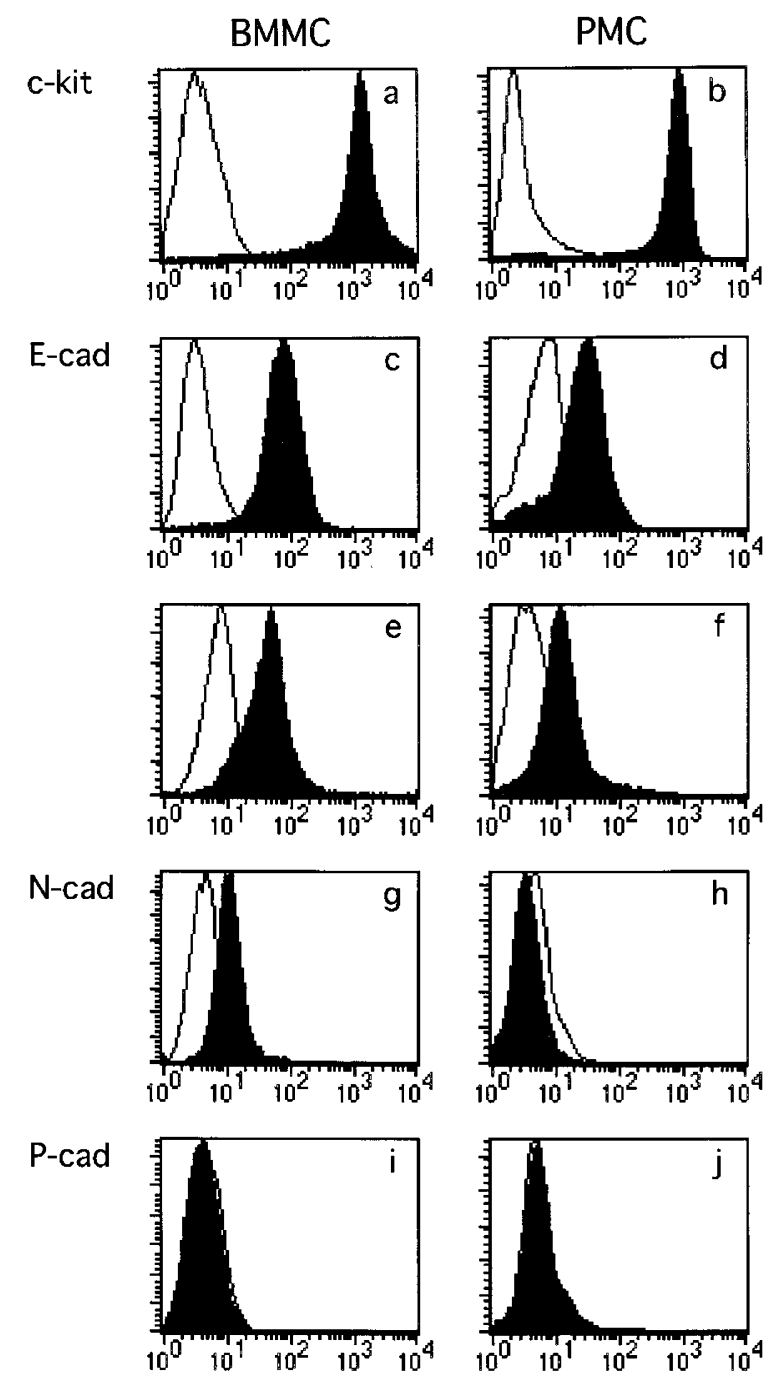

\section{Figure 1}

FACS analysis of E-, N-, and P-cadherin on bone marrow-derived cultured mast cells (BMMC) and peritoneal mast cells (PMC). $a$ and $b$, Cells were stained with PE-conjugated anti-c-kit mAb. $c$ and $d$, Cells were incubated with anti-Ecadherin mAb (ECCD)-2, followed by FITC-labeled antirat IgG1. $e$ to $j$, Cells were first incubated with rat mAb against mouse CD16/32. After washing, cadherins were detected by incubation with biotinylated ECCD-2, anti-Ncadherin mAb (GC-4), or anti-P-cadherin mAb (PCD-1), followed by FITCconjugated streptavidin. For control staining, irrelevant isotype-matched control antibodies were employed. Open histogram, isotype-matched control; solid histogram, c-kit or cadherins. The results shown are representative of five experiments.

\section{Expression of Cadherin-Associated Proteins in Mast Cells}

Classic cadherins form complexes via their cytoplasmic domains with several proteins such as $\alpha$ - and $\beta$-catenins and the tyrosine kinase substrate $\mathrm{p} 120$. To determine whether mast cells also express cadherinassociated proteins, cytosolic extracts were prepared from BMMC and PMC, and Western blotting analysis was performed. Immunoblotting of BMMC extract (30 $\mu \mathrm{g}$ ) demonstrated $\mathrm{E}$ - and $\mathrm{N}$-cadherin as well as $\alpha$ - and $\beta$-catenin molecules (Fig. 5A), whereas analyses using the same amount of protein extract from PMC failed to detect either cadherins or $\alpha$ - or $\beta$-catenin, except p120. In PMC extract, weak E-cadherin and $\alpha$ - and 
BMMC
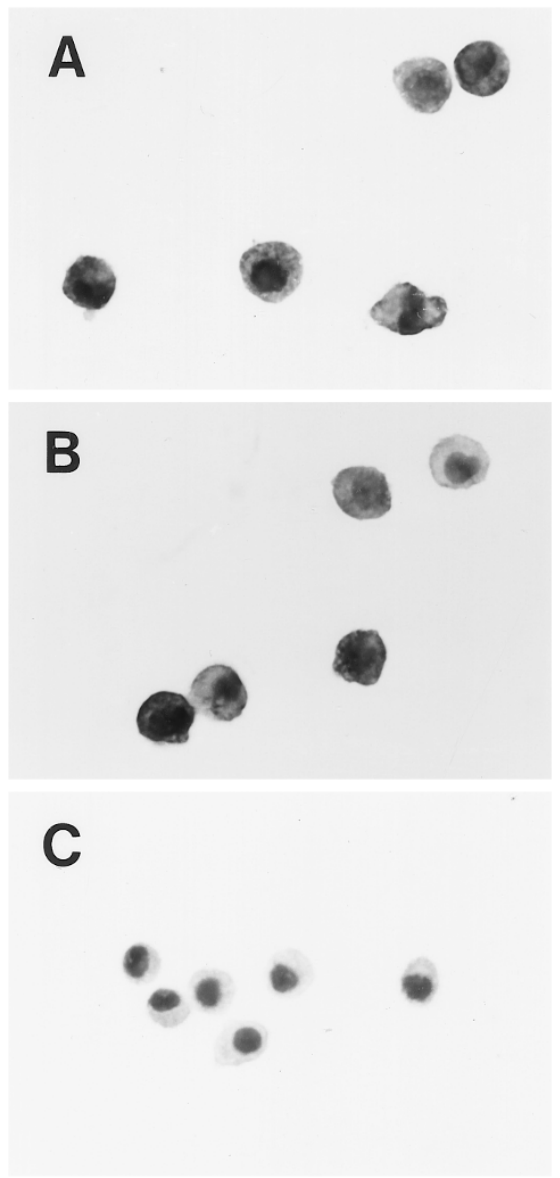

PMC

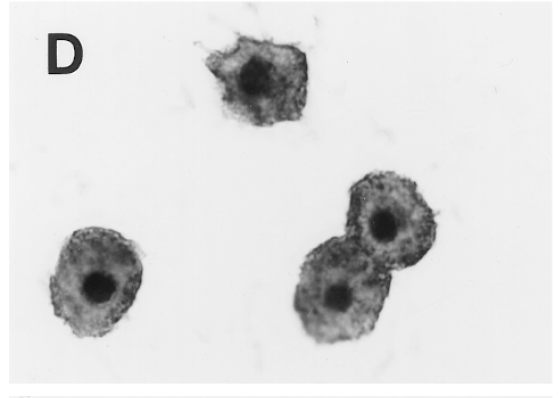

E

$\mathbf{F}$

\section{Figure 2.}

Immunocytochemical staining of cadherins in BMMC $(A$ to $C)$ and PMC $(D$ to $F)$. $A$ and $D$, E-cadherin expression, showing E-cadherin immunoreactivity in the cell membrane and cytoplasm of both cell types. $B$ and $E$, N-cadherin expression. N-cadherin immunoreactivity was seen in BMMC, but not in PMC. $C$ and $F, B M M C$ or PMC incubated with normal immunoglobulin. Nuclei were stained with hematoxylin. Magnification, $\times 750$.
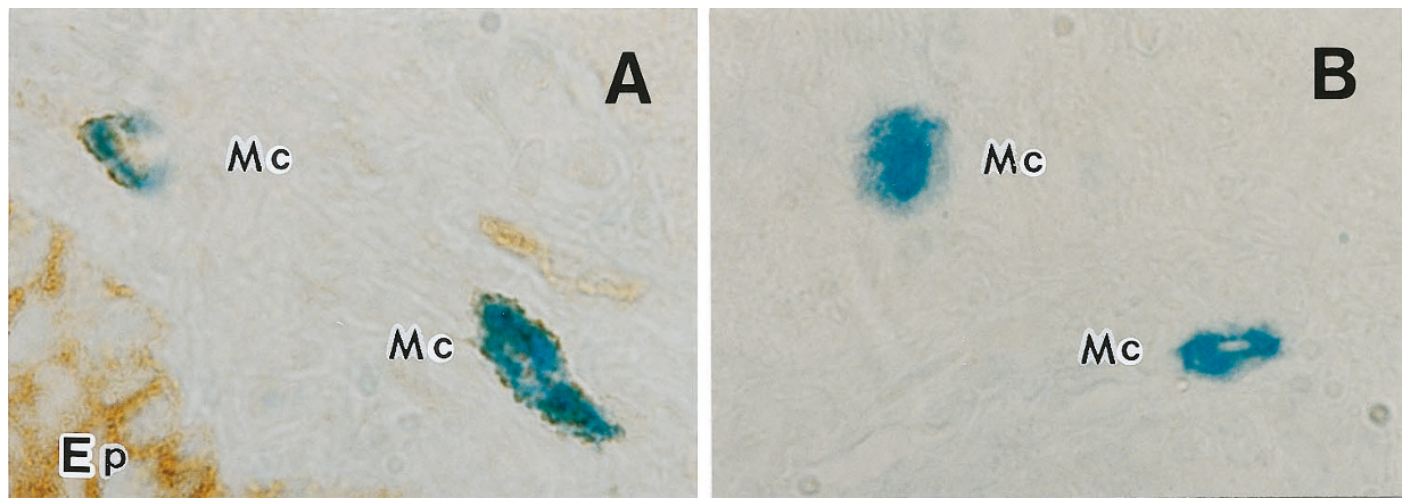

Figure 3.

Immunohistochemical staining of E-cadherin in the tongue. $A$, E-cadherin immunostaining. Mast cells $(M c)$ were visualized by staining with alcian blue. E-cadherin was detected on the mast cell membrane as well as at epithelial cell-cell borders $(E p)$. B. Section incubated with isotype-matched control immunoglobulin. Magnification, $\times 1,000$.

$\beta$-catenin expression were detected when larger amounts of protein extract $(80 \mu \mathrm{g})$ were subjected to immunoblotting analyses (Fig. 5A). It has been reported that $\mathrm{p} 120$ has at least four isoforms, ie CAS-1A (approximately $115 \mathrm{kDa}),-1 \mathrm{~B}(112 \mathrm{kDa}),-2 \mathrm{~A}(105$ $\mathrm{kDa})$, and -2B (90 kDa) (Reynolds et al, 1994). Immunoblotting, using an anti-p120 antibody that recognizes all isoforms, revealed immunoreactive bands 

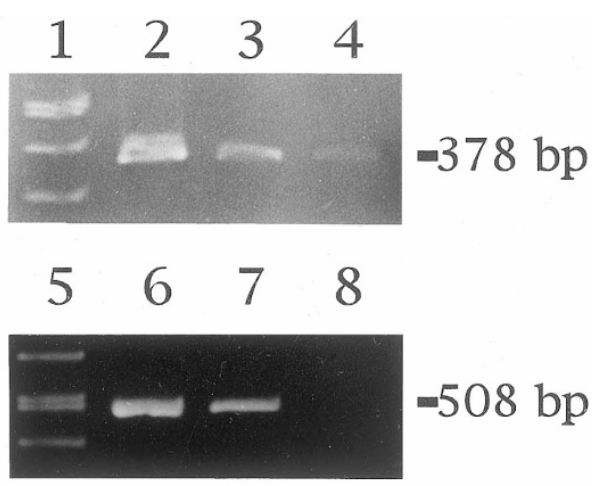

Figure 4.

$\mathrm{E}-$ and $\mathrm{N}$-cadherin mRNA expression in mouse BMMC and PMC detected by RT-PCR. Lanes 2 to 4, E-cadherin expression in mouse testes (2), BMMC (3), and PMC (4). Lanes 6 to 8, N-cadherin expression in mouse testes (6), BMMC (7), and PMC (8). In PMC, N-cadherin message was undetectable. Lanes 1 and 5 represent 100-bp DNA ladder.

between 90 and $115 \mathrm{kDa}$, but the pattern of isoform expression was not identical between BMMC and PMC (Fig. 5A).

To determine whether cadherin-catenin complex is formed in mast cells, BMMC lysates were immunoprecipitated using anti- $\beta$-catenin antibody, and the precipitate was subjected to immunoblotting analysis. As shown in Figure 5B, $\beta$-catenin immunoprecipitate revealed E-cadherin and $\alpha$-catenin together with $\beta$-catenin. Immunoblotting analysis of the immunoprecipitate obtained using anti-E-cadherin also showed $\beta$-catenin and $\alpha$-catenin together with E-cadherin. Isotype-matched control antibody did not yield signals for $\beta$-catenin, E-cadherin, or $\alpha$-catenin (Fig. 5B).

\section{Suppression of Mast Cell Colony Formation by Anti-E-Cadherin Antibody or Synthetic E-Cadherin-Binding Decapeptides In Vitro}

Armeanu et al (1995) reported that the addition of anti-E-cadherin antibody to bone marrow cell cultures markedly reduced the formation of erythropoietic cells. Methylcellulose culture of bone marrow cells with appropriate growth factors produces colonies of, not only mast cells, but also granulocytes and macrophages, whereas the same culture of intraepithelial mononuclear cells (IEMNC) separated from mouse small intestine yields only pure mast cell colonies in the presence of pokeweed mitogen-stimulated spleen cell-conditioned medium (PWM-SCF) (Tegoshi et al, 1997). Thus, first we analyzed effects of ECCD-1, which blocks homophilic E-cadherin interactions (Shirayoshi et al, 1986; Yoshida-Noro et al, 1984), on the mast cell colony formation from IEMNC. FACS analysis of mast cells which developed from IEMNC in methylcellulose cultures revealed expression of c-kit as well as of E-cadherin (Fig. 6, A and B). Immunoblotting analysis of IEMNC-derived mast cells also showed E-cadherin protein (data not shown). Addition of ECCD-1 to methylcellulose cultures of IEMNC resulted in dose-dependent suppression of the development of mast cell colonies (Fig. 7A). Total numbers

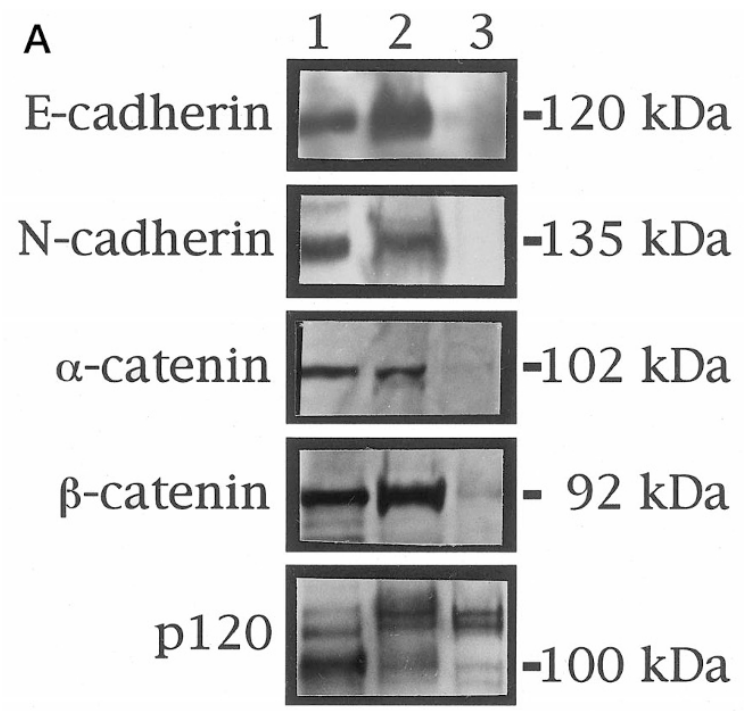

B $\beta$-catenin E-cadherin immunoprecipitation immunoprecipitation
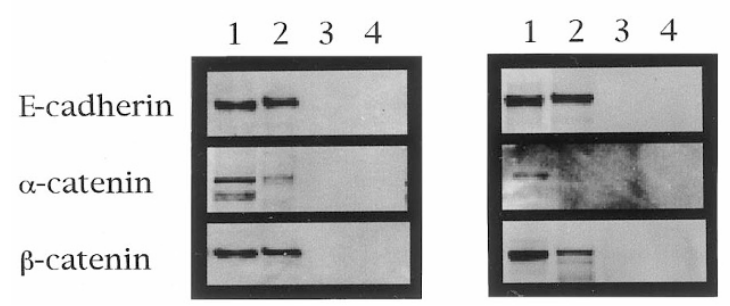

\section{Figure 5.}

Immunoblotting analysis of cadherins and catenins in mast cells. $A$, Immunoblotting analysis of whole-cell lysate of BMMC (lane 2) or PMC (lane 3). Lane 1 shows positive control for cadherins and catenins (rat small intestine epithelial cell line [IEC]-6 cell lysate for E-cadherin, human neuroblastoma cell line [KPN-RT] lysate for N-cadherin, HeLa cell lysate for $\alpha$ - and $\beta$-catenin, and A431 cell lysate for p120). BMMC showed high levels of expression of E- and $\mathrm{N}$-cadherin, $\alpha$ - and $\beta$-catenin, and $\mathrm{p} 120$, whereas PMC showed low levels of expression of E-cadherin and $\alpha$ - and $\beta$-catenin, and a high level of $\mathrm{p} 120$ expression. $B$, Immunoblotting analysis of $\mathrm{E}$-cadherin or $\beta$-catenin immunoprecipitate. BMMC extracts were incubated with antibody specific for $\mathrm{E}$-cadherin (lane 2) or $\beta$-catenin (lane 2), isotype-matched control antibodies (lanes 3), or without antibody (lanes 4). The immunoprecipitates or control samples were subjected to immunoblotting analysis for E-cadherin, $\alpha$-catenin, and $\beta$-catenin. Lanes 1 show positive controls as indicated in Figure $5 \mathrm{~A}$. The results are representative of three experiments.
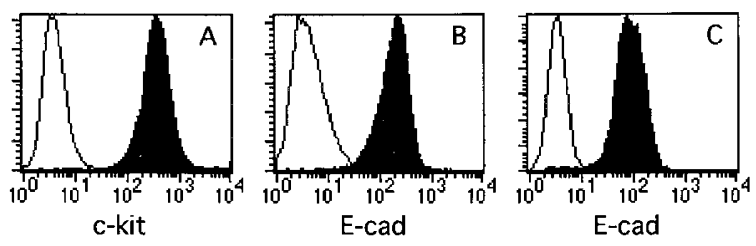

Figure 6.

FACS analysis of $\mathrm{c}$-kit $(A)$ and $\mathrm{E}$-cadherin $(B)$ in intraepithelial mononuclear cells (IEMNC)-derived mast cells, and expression of E-cadherin in F9 cells (C). Mast cells were collected from colonies derived from IEMNC. F9 cells were isolated by EDTA treatment. c-kit was detected as described in Figure 1, a and $\mathrm{b}$, and E-cadherin was detected as described in Figure 1, $\mathrm{c}$ and $\mathrm{d}$.

of mast cells recovered from methylcellulose cultures were also significantly less than in control cultures (Fig. 7B). To determine whether the suppression of 
mast cell clonal growth was mediated by the cadherin homophilic binding domain, we compared the effects of ECCD-1 and ECCD-2, the latter of which has been reported to recognize the extracellular domain of E-cadherin but does not block homophilic E-cadherin interactions (Karecla et al, 1995). As shown in Figure $7 C$, ECCD-2 did not suppress the clonal growth of mast cells. Addition of a synthetic decapeptide (Ecadherin peptide 232-41) containing the cadherin cell adhesion recognition sequence HAV into methylcellulose cultures also resulted in dose-dependent suppression of mast cell colony formation as well as reduction of total mast cell numbers, whereas E-cadherin peptide 159-68, which does not have the HAV sequence, did not (Fig. 7, D and E). Addition of P-cadherin peptide 175-84 containing the HAV se-
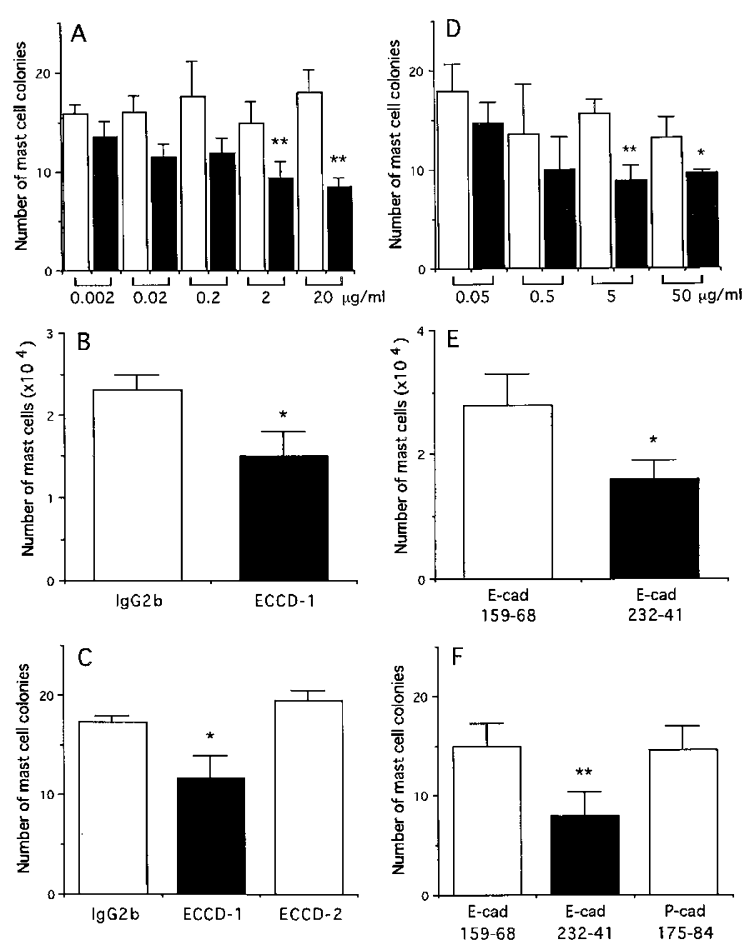

Figure 7.

Effects of anti-E-cadherin antibodies and synthetic decapeptides on mast cell colony formation from IEMNC. IEMNC were isolated from mouse small intestine and cultured in methylcellulose in the presence of mAbs or synthetic peptides. A, ECCD-1 (closed columns) or control rat IgG2b (open columns) was added to the cultures at indicated concentrations, and the number of mast cell colonies that developed after 10 days was determined. $B$, All cells were harvested from culture wells with $20 \mu \mathrm{g} / \mathrm{ml}$ antibodies in $A$ and total number of mast cells per well was determined. $C, 20 \mu \mathrm{g} / \mathrm{ml}$ of ECCD-1, ECCD-2, or rat $\lg \mathrm{G} 2 \mathrm{~b}$ was added to the cultures, and the number of mast cell colonies that developed after 10 days was determined. $D$, Synthetic E-cadherin decapeptide 159-68 (open columns) or 232-41 with histidine-alanine-valine (HAV) sequence (closed columns) was added to the cultures at the indicated concentrations, and the number of mast cell colonies was determined after 10 days. $E$, All cells were harvested from culture wells with $50 \mu \mathrm{g} / \mathrm{ml}$ synthetic decapeptide in $D$, and the total number of mast cells per well was determined. $F, 50 \mu \mathrm{g} / \mathrm{ml}$ of E-cadherin peptide 159-68, E-cadherin peptide 232-41, or P-cadherin peptide 175-84 was added to the cultures, and the number of mast cell colonies was determined after 10 days. Columns and bars represent means \pm SD of four cultures. ${ }^{* *}$ Significantly different from the corresponding value for isotype-matched control IgG or E-cadherin peptide $159-68\left({ }^{*} p<\right.$ $\left.0.05,{ }^{* *} p<0.01\right)$. Similar results were obtained in three independent experiments. quence also showed no suppressive effect on mast cell colony formation (Fig. 7F).

Subcultures of BMMC, which had been maintained in suspension culture for 4 weeks, also yielded pure mast cell colonies in methylcellulose culture. Addition of ECCD-1 or E-cadherin peptide 232-41 into methylcellulose media suppressed the clonal growth of mast cells, whereas ECCD-2, E-cadherin peptide 159-68, or $\mathrm{P}$-cadherin peptide 175-84 did not suppress mast cell colony formation (Fig. 8, A and B). There was no significant suppression of the proliferation of BMMC by direct addition of ECCD-1 to suspension cultures for 5 days, although slight but significant suppression of the proliferation of BMMC was observed on Day 3 in 2 of 5 experiments (data not shown).

\section{Role of Mast Cell E-Cadherin in Cell-Cell Adhesion}

To determine whether mast-cell E-cadherin has a role in cellular adhesion, we studied the adhesion of BMMC to F9 cell monolayers, which constitutively express E-cadherin (Fig. 6C). It has been reported that intercellular $\mathrm{Ca}^{2+}$-dependent adhesion of $\mathrm{F9}$ cells was inhibited by $\leq 200 \mu \mathrm{g} / \mathrm{ml}$ ECCD-1 (Yoshida-Noro et al, 1984). To find appropriate concentrations of ECCD-1 at which the F9 cell monolayer itself would not be dissociated, we first examined the direct effects of ECCD-1 and E-cadherin peptide 232-41 on monolayers of F9 cells labeled with 2', 7'-bis-(2carboxyethyl)-5 (and -6)-carboxyfluorescein (BCECFAM). Addition of up to $20 \mu \mathrm{g} / \mathrm{ml}$ ECCD- 1 or E-cadherin peptide 232-41 induced neither desquamation of F9 cells from culture dishes in microscopic examinations nor reduction of the BCECF-AM fluorescence intensity of adherent F9 cells, at least not within 30 minutes of incubation (data not shown). Thus, we examined binding of BCECF-AM-labeled BMMC to nonlabeled F9 cell monolayers in the presence or absence of 20 $\mu \mathrm{g} / \mathrm{ml}$ mAbs or peptides. Approximately $50 \%$ to $60 \%$ of BMMC adhered to the F9 monolayer within 30 minutes in the presence of control immunoglobulin G2b (IgG2b). This binding was significantly suppressed by addition of ECCD-1, but not ECCD-2 (Fig. 9A). E-cadherin peptide 232-41 also suppressed BMMC binding, whereas E-cadherin peptide 159-68 or P-cadherin peptide 175-84 did not (Fig. 9B).

\section{Discussion}

E-cadherin is expressed not only on epithelial cells but also on certain nonepithelial cells such as Langerhans dendritic cells, murine cutaneous $\mathrm{v} \gamma 5^{+} \gamma / \delta \mathrm{T}$ cells, $\mathrm{CD}^{+} / \mathrm{CD}^{+}$thymocytes, and erythroblasts and normoblasts in the bone marrow (Aiba et al, 1995; Armeanu et al, 1995; Caux et al, 1996; Munro et al, 1996). The present study showed that E-cadherin was also expressed in cultured murine mast cells, as well as in freshly isolated PMC. The conserved cytoplasmic domain of cadherins is known to associate with $\alpha-, \beta$-, and $\gamma$-catenins (Ozawa et al, 1989) as well as with $\mathrm{p} 120$, originally identified as a tyrosine kinase substrate of the oncogenic Src tyrosine kinase (Reyn- 

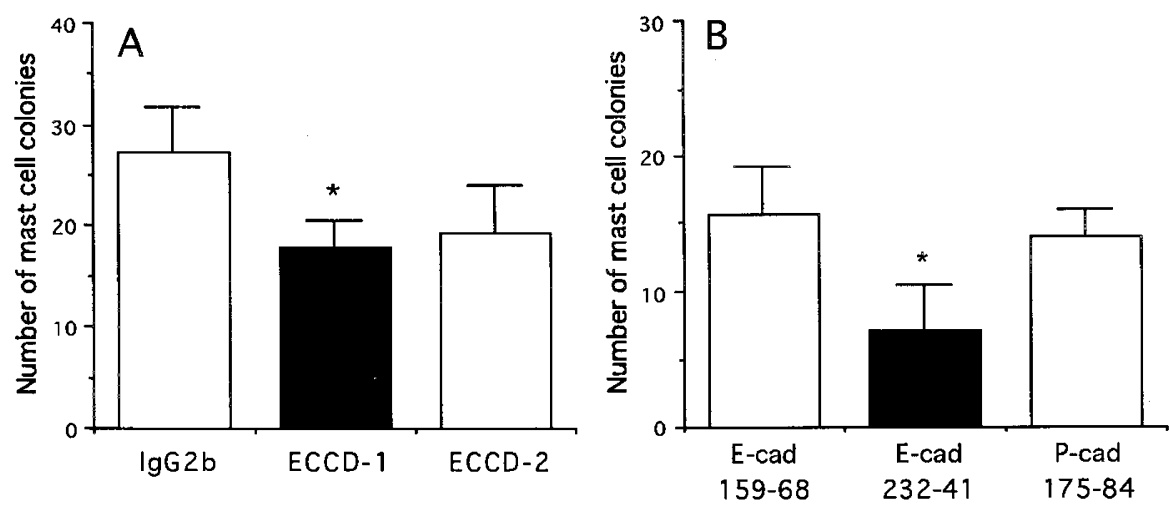

Figure 8.

Effects of anti-E-cadherin antibody and synthetic decapeptides on mast cell colony formation from BMMC. BMMC maintained in suspension culture were transferred into methylcellulose media, together with mAbs or peptides, and incubated for 10 days. $A$, Number of mast cell colonies generated in the presence of $20 \mu \mathrm{g} / \mathrm{ml}$ of ECCD-1, ECCD-2, or control rat IgG2b. B, Number of mast cell colonies generated in the presence of $50 \mu \mathrm{g} / \mathrm{ml}$ of E-cadherin peptide 159-68, E-cadherin peptide 232-41, or P-cadherin peptide 175-84. * Significantly different from the corresponding value for isotype-matched control IgG or E-cadherin peptide $159-68\left({ }^{\star} p<\right.$ $0.05)$.
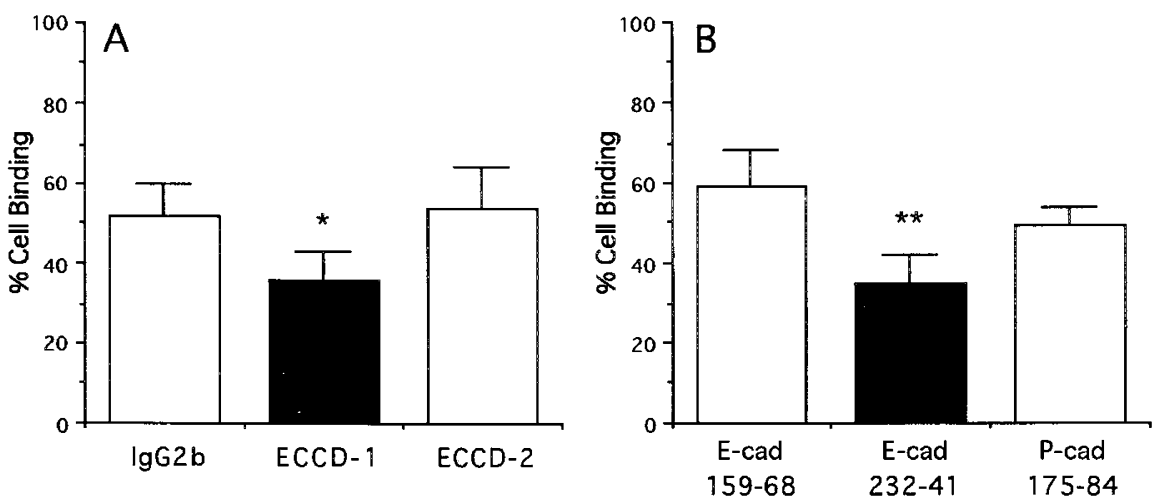

Figure 9.

Effects of anti-E-cadherin antibodies and synthetic decapeptides on adhesion of BMMC to F9-cell monolayers. BCECF-AM-labeled BMMC were preincubated for 30 minutes with $20 \mu \mathrm{g} / \mathrm{ml}$ of indicated antibodies or peptides and then co-cultured with nonlabeled F9 cell monolayers in the presence of the same amounts of antibodies or peptides. Percentages of binding of BMMC were determined by measuring fluorescence intensity after removing unbound cells in reference to the standard curve produced using known numbers of labeled BMMC. $A$, BMMC binding rate to $\mathrm{F} 9$ cells in the presence of ECCD-1, ECCD-2, or control rat IgG2b. $B$, BMMC binding rate to F9 cells in the presence of E-cadherin peptide 159-68, E-cadherin peptide $232-41$, or P-cadherin peptide 175-84. Bars represent SD of four cultures. */** Significantly different from the corresponding value for isotype-matched control IgG or E-cadherin peptide $159-68\left({ }^{\star} p<0.05,{ }^{\star \star} p<0.01\right)$.

olds et al, 1994; Shibamoto et al, 1995). The cadherincatenin complex forms a functional unit for $\mathrm{Ca}^{2+}$ dependent cell-cell adhesion (Nagafuchi and Takeichi, 1988). BMMC also showed $\alpha$ - and $\beta$-catenin and $\mathrm{p} 120$ expression. Furthermore, $\alpha$-catenin and E-cadherin co-precipitated with $\beta$-catenin, and $\alpha$ - and $\beta$-catenin co-precipitated with E-cadherin on immunoprecipitation of $\beta$-catenin and $E$-cadherin, respectively. These results suggested that mast cells express E-cadherin and cadherin-associated cytoplasmic proteins as a functional complex.

Certain malignant lymphoma cell lines, such as adult $\mathrm{T}$ cell lymphomas and thymus-derived lymphomas, express $\mathrm{N}$-cadherin and associated catenins (Kawamura et al, 1998; Tsutsui et al, 1996). BMMC also exhibited expression of $\mathrm{N}$-cadherin together with E-cadherin. In contrast, PMC, representative of mature mast cells, did not express $\mathrm{N}$-cadherin. In addition, the levels of expression of E-cadherin and catenins on PMC were low compared to those of BMMC. Cadherin expression is regulated both spa- tially and temporally during development. For instance, neural tube cells lose E-cadherin and acquire $\mathrm{N}$-cadherin during early development (Hatta and Takeichi, 1986). In erythroid cells, erythroblasts and normoblasts express E-cadherin, whereas mature erythrocytes do not (Armeanu et al, 1995; Buhring et al, 1996). Thus, mast cells seem to express both Eand $\mathrm{N}$-cadherin, at least in certain stages of proliferation and differentiation, but, after maturation, $\mathrm{N}$-cadherin expression might be suppressed and a low level of E-cadherin expression may persist.

E-cadherin expressed in epithelial cells participates in cell recognition and sorting during developmental morphogenesis and in maintenance of tissue integrity through $\mathrm{Ca}^{2+}$-dependent cell-cell adhesion. E-cadherins have also been implicated in a number of biological processes, including cell growth and differentiation, as well as in aggregation-dependent cell survival (Pece et al, 1999). Armeanu et al (1995) reported that addition of anti-E-cadherin antibody to bone marrow mononuclear cell cultures containing 
exogenous erythropoietin markedly reduced the formation of erythropoietic cells, suggesting that stimulation through E-cadherin, which is expressed at certain stages in the erythropoietic lineage, might have some link to a signal transduction molecule in the differentiation or proliferation process. The present results showed that addition of anti-E-cadherin antibody ECCD-1, as well as E-cadherin decapeptide with the HAV sequence, dose-dependently suppressed mast cell colony formation from BMMC or IEMNC in methylcellulose cultures. It seems likely that the E-cadherin binding domain is linked to the clonal expansion of mast cells, because ECCD-2 (which recognizes the extracellular domain of E-cadherin but does not block homophilic E-cadherin binding), E-cadherin peptide without the HAV sequence, or P-cadherin peptide with the HAV sequence did not suppress mast cell colony formation. This latter result, ie, that P-cadherin peptide did not suppress mast cell colony formation, is consistent with reports that heterophilic cadherin binding (eg, E-cadherin and P-cadherin) does not occur (Takeichi, 1995). However, proliferation of BMMC in suspension cultures was not significantly suppressed by ECCD-1, although in a few experiments slight and transient suppression was observed. The reason for this discrepancy is not clear at present. It is possible that E-cadherin is needed for cell-cell association to form colonies, but is not indispensable for cell differentiation and/or proliferation. However, the present results also showed that in methylcellulose cultures, addition of ECCD-1 or E-cadherin peptide with HAV sequence resulted in, not only reduction of colony numbers, but also reduction of numbers of generated mast cells. Thus, cell recognition through $\mathrm{E}$-cadherin might be involved in the differentiation/proliferation process, especially of those cells that could produce mast cell colonies. We occasionally found large, almost pure mast-cell clusters in the lamina propria mucosa of the rat small intestine after nematode infection, although clonality of the clusters was undefined (unpublished observations). In Mongolian gerbils, we also reported formation of basophilic cell clusters after nematode infection (Okada et al, 1997). The in vivo significance of E-cadherin-mediated regulation of colony formation should be clarified in future studies. It has been reported that E-cadherin can initiate outside-in signal transducing pathways that regulate the activity of phosphatidylinositol 3 (PI3) kinase and protein kinase Akt, which play critical roles in cell survival (Pece et al, 1999). On the other hand, the signal transduction pathways in cadherin-mediated cell differentiation and/or proliferation still remain to be elucidated.

The observation that mast cells do not form tight adhesion (or compaction) between individual cells in vivo, as well as in vitro, indicated that levels of E-cadherin expression in mast cells are not as high as those in epithelial cells. In fact, immunostaining of E-cadherin showed that its expression in tongue mast cells was not as strong as that in squamous epithelium. However, it is possible that E-cadherin plays some role in the homing of mast cells to tissues such as the gut or respiratory epithelium where E-cadherin is constitutively expressed. Although these are still preliminary observation, our results showed that ECCD-1, as well as E-cadherin peptide with the HAV sequence, partly but significantly suppressed the binding of BMMC to E-cadherin-expressing F9 cells, whereas neither ECCD-2 nor E-cadherin without HAV or P-cadherin peptide showed such an effect. These results suggested that in certain conditions E-cadherin mediates at least partially the binding of mast cells to epithelial cells.

Taken together, the present results showed that mast cells express cadherins and catenins, and these molecules might be involved in the regulation of some biological processes of mast cells such as differentiation and/or proliferation and cell recognition.

\section{Materials and Methods}

\section{Animals}

Female BALB/c mice, 8 weeks and 20 to 25 weeks old, were purchased from Japan SLC Inc., Hamamatsu, Japan.

\section{Antibodies and Reagents}

Rat mAb against mouse E-cadherin, ECCD-1 ( $\mathrm{NaN}_{3}-$ free), and ECCD-2 ( $\mathrm{NaN}_{3}$-free) were purchased from Takara Biomedicals (Shiga, Japan), and clone 36 was from Transduction Laboratories (Lexington, California). Anti-N-cadherin mouse mAb (GC-4) and affinitypurified rabbit polyclonal antibody against $\mathrm{N}$-cadherin were purchased from Sigma BioSciences (St. Louis, Missouri) and Takara Biomedicals, respectively. Anti$\mathrm{P}$-cadherin mAb (PCD-1) was purchased from Takara Biomedicals. Anti- $\alpha-, \beta$-catenin, and p120 mAb were purchased from Transduction Laboratories. R-phycoerythrin (PE)-conjugated anti-c-kit receptor (CD117) antibody was purchased from Pharmingen (San Diego, California). Fluorescein isothiocyanate (FITC)-conjugated anti-rat IgG and FITC-conjugated anti-mouse IgG were purchased from Serotec Ltd. (Oxford, United Kingdom) and Leinco Technologies Inc. (Ballwin, Missouri), respectively. Peroxidaseconjugated anti-rat IgG was purchased from Wako Pure Chemical Industries Ltd. (Osaka, Japan), and peroxidase-labeled dextran polymer conjugated with anti-mouse Ig (EnVision+ for mouse) or with antirabbit Ig (EnVision+ for rabbit) were from DAKO Company (Carpinteria, California).

Synthetic decapeptides, VIPPISCPEN and LYSHAVSSNG, the sequence of which corresponded to the first extracellular domain of mouse E-cadherin amino acid residues 159-68 and 232-41, respectively, and LYGHAVSENG, the sequence of which corresponded to the first extracellular domain of mouse $\mathrm{P}$-cadherin amino acid residues 175-84 were obtained from Sawady Technology (Tokyo, Japan).

\section{Mast Cells}

BMMC were obtained as described previously (Tegoshi et al, 1997). Briefly, bone marrow cells ob- 
tained from the femurs of 8-week-old mice were cultured at $37^{\circ} \mathrm{C}$ in a humidified $5 \% \mathrm{CO}_{2}$ atmosphere in $\alpha$-MEM supplemented with $10 \%(\mathrm{v} / \mathrm{v})$ FBS, $10^{-4} \mathrm{M}$ 2-mercaptoethanol (2-ME), $100 \mathrm{IU} / \mathrm{ml}$ penicillin, 100 $\mu \mathrm{g} / \mathrm{ml}$ streptomycin, and $10 \%$ (v/v) pokeweed mitogen-stimulated spleen cell-conditioned medium (PWM-SCM). Medium was exchanged every 4 to 5 days. Mast cells with more than $95 \%$ purity after 4 weeks in culture were used for the present study.

PMC were isolated according to the method of Enerbäck and Svensson (1980) with slight modifications. Briefly, peritoneal cells were recovered by lavage of the peritoneal cavity of 20 - to 25 -week-old mice with Hanks' balanced salt solution with $0.1 \%$ BSA (HBSS-BSA). Peritoneal cells resuspended in 1.5 $\mathrm{ml}$ of HBSS-BSA were mixed with $3.5 \mathrm{ml}$ of isotonic Percoll (Pharmacia Fine Chemicals AB, Uppsala, Sweden) solution; a layer of $0.5 \mathrm{ml}$ of HBSS-BSA was then added and centrifuged at $500 \times g$ for 20 minutes at room temperature. Cells collected from the bottom of the tube consisted of mast cells with greater than $95 \%$ purity.

\section{FACS Analysis}

FACS analysis of cadherins was carried out in the presence or absence of the blocking agent of FC receptors on mast cells. In experiments omitting Fc receptor blocker, aliquots of $2 \times 10^{5} \mathrm{BMMC}$ or $\mathrm{PMC}$ were incubated with ECCD-2, GC-4, or PCD-1, which recognize the extracellular domains of $\mathrm{E}-, \mathrm{N}-$, and $\mathrm{P}$-cadherin, respectively, in a buffer containing PBS, 1 mм $\mathrm{CaCl}_{2}$, and $1 \% \mathrm{BSA}$ (PBS-Ca-BSA) for 30 minutes at $4^{\circ} \mathrm{C}$. Cells were washed three times in PBS followed by incubation with FITC-conjugated rabbit antirat IgG antibody for E- and P-cadherin or with FITCconjugated anti-mouse IgG for N-cadherin in PBS-CaBSA for 30 minutes at $4^{\circ} \mathrm{C}$. In FACS analysis of cells with blocking $\mathrm{Fc}$ receptor, BMMC or PMC were first incubated with rat mAb against mouse CD16/32 (1 $\mu \mathrm{g} / 1 \times 10^{6}$; Fc Block, Pharmingen) for 10 minutes at $4^{\circ} \mathrm{C}$. After washing with PBS, cells were incubated with biotinylated-ECCD-2, -GC-4, or -PCD-1, followed by incubation with FITC-conjugated streptavidin, because FITC-conjugated anti-lgG antibody gave high background fluorescence in cells incubated with CD16/32 antibody. For c-kit staining, cells were incubated with PE-conjugated anti-c-kit receptor antibody for 30 minutes. Cells were washed in PBS and analyzed for surface antigen expression using a FACScan flow cytometer and CellQuest software (Becton Dickinson, Mansfield, Massachusetts). Surface antigen levels were expressed as mean fluorescence intensity of cells. Negative controls included isotype-matched irrelevant antibodies or direct staining with secondary antibody in the absence of the first antibody.

\section{Immunohistochemistry}

$\mathrm{BMMC}$ or $\mathrm{PMC}$ were fixed with $1 \%$ glutaraldehyde in PBS for 30 minutes at $4^{\circ} \mathrm{C}$, washed with PBS, and cytospin preparations were made. The slides were incubated with $10 \%$ normal goat serum in PBS for 1 hour, and then with ECCD-2, affinity-purified anti-Ncadherin rabbit IgG or PCD-1 at $37^{\circ} \mathrm{C}$ for 60 minutes. After washing, the slides were incubated with peroxidase-conjugated goat anti-rat IgG for E- and $\mathrm{P}$-cadherin or with anti-rabbit IgG for $\mathrm{N}$-cadherin at $37^{\circ} \mathrm{C}$ for 30 minutes, and DAB reaction was carried out. Nuclei were counterstained with hematoxylin.

Immunohistochemical staining for E-cadherin on formalin-fixed paraffin-embedded sections was carried out as follows. Dewaxed sections were treated with $0.3 \% \mathrm{H}_{2} \mathrm{O}_{2}$ for 20 minutes, then immersed in $0.01 \mathrm{M}$ sodium citrate buffer, $\mathrm{pH} 6.0$, in plastic Coplin jars and incubated in a YS-A-C105 autoclave (Yuyama Company, Toyonaka, Japan) at $121^{\circ} \mathrm{C}$ for 10 minutes. The slides were then incubated with ECCD-2 or clone 36 at $37^{\circ} \mathrm{C}$ for 1 hour, followed by incubation with peroxidase-conjugated anti-rat IgG or EnVision+ for mouse, and DAB reaction was carried out. Mast cells were counterstained with $1 \%$ alcian blue in 3\% acetic acid. As negative controls, isotype-matched immunoglobulins (rat IgG1 or mouse IgG2a) were employed.

\section{Isolation of Total RNA}

BMMC $\left(1 \times 10^{7}\right)$ or PMC $\left(5 \times 10^{5}\right)$ were homogenized in $1 \mathrm{ml}$ of ISOGEN solution (Nippongene, Tokyo, Japan), and RNA was extracted with chloroform and precipitated with ethanol. RNA was also extracted from mouse testes as a positive control of $\mathrm{E}$ - and $\mathrm{N}$-cadherin expression (Munro and Blaschuk 1996). PMC-derived RNA samples were treated with heparinase before cDNA production as previously described (Gilchrist et al, 1997). Briefly, $0.5 \mu \mathrm{g}$ aliquots of total RNA extracted from PMC were incubated with $2.5 \mathrm{U}$ of heparinase I (Sigma) in reaction mixtures containing 5 $\mathrm{mm}$ Tris (pH 7.5), $1 \mathrm{~mm} \mathrm{CaCl}_{2}$, and $50 \mathrm{U}$ RNAsin (Gibco/BRL, Grand Island, New York) for 2 hours at $22^{\circ} \mathrm{C}$.

\section{Reverse Transcription Reaction}

Aliquots of $5 \mu \mathrm{g}$ of total RNA from BMMC or $0.5 \mu \mathrm{g}$ of total RNA from PMC were mixed with oligo (dT)12-18 $(500 \mu \mathrm{g} / \mathrm{ml})$ and then diluted to $7 \mu$ with DEPC-DW. These mixtures were heated to $65^{\circ} \mathrm{C}$ for 5 minutes and chilled quickly on ice. To the contents of the sample tubes were added $4 \mu$ l of first strand buffer (375 mM KCl, $250 \mathrm{~mm}$ Tris- $\mathrm{HCl}$, and $15 \mathrm{~mm} \mathrm{MgCl}_{2}$ ), $1 \mu \mathrm{l}$ of $2.1 \mathrm{U} / \mu \mathrm{l}$ Ribonuclease $\mathrm{H}$ (RNase $\mathrm{H}), 4 \mu \mathrm{l}$ of mixed dNTPs (2.5 mm each dATP, dGTP, dCTP, dTTP), and $2 \mu \mathrm{l}$ of $100 \mathrm{~mm}$ dithiothreitol. After 5 minutes of preincubation at $42^{\circ} \mathrm{C}, 1 \mu \mathrm{l}$ of $200 \mathrm{U} / \mu$ l SuperScript II RNase $H$ Reverse Transcriptase (Life Technologies Inc., Gaithersburg, Maryland) was added and further incubated at $42^{\circ} \mathrm{C}$ for 50 minutes, then $95^{\circ} \mathrm{C}$ for 5 minutes, and chilled on ice.

\section{PCR}

PCR was carried out by adding $1 \mu \mathrm{l}$ of CDNA product to $29 \mu$ l of PCR buffer containing $100 \mathrm{~mm}$ Tris ( $\mathrm{pH} 8.3$ ), $500 \mathrm{~mm} \mathrm{KCl}, 15 \mathrm{~mm} \mathrm{MgCl}_{2}$, mixed dNTPs at $2.5 \mathrm{~mm}, 5$ 
$\mathrm{U} / \mu \mathrm{l}$ Taq polymerase $(\times 10)$, and $1.5 \mu \mathrm{M}$ of $3^{\prime}$ and $5^{\prime}$ primers $(20 \mathrm{pm} / \mu \mathrm{l})$. Amplification was performed using a Perkin-Elmer/Cetus DNA thermal cycler (Norwalk, Connecticut). The reaction was conducted for 30 cycles at $90^{\circ} \mathrm{C}$ for 1 minute, $55^{\circ} \mathrm{C}$ for 2 minutes, and $72^{\circ} \mathrm{C}$ for 2 minutes. PCR products were electrophoresed on $3.5 \%$ agarose gels and visualized by staining with ethidium bromide. The sequences of the sense and antisense primers for E-cadherin were $5^{\prime}$ ACGTATCAGGGTCAAGTGCC-3' and 5'-CCTGACCCACACCAAAGTCT-3', respectively; the former corresponded to bases 1209 to 1228 and the latter was complementary to bases 1565 to 1584 of mouse E-cadherin-cDNA sequence (EMBL/GenBank $\times 06115$; EMBL, Heidelberg, Germany) (Nagafuchi et al, 1987). This primer pair provided a 378-base pair product. For $\mathrm{N}$-cadherin, the sense primer 5'GGGACAGGAACACTGCAAATC-3' and antisense primer 5'-GCTTGGCGCTCTITATCCCG-3' were used. The sequences corresponded to bases 2091 to 2111 and 2577 to 2596, respectively, of mouse $\mathrm{N}$-cadherin-cDNA sequence (EMBL/GenBank M31131, M22556) (Miyatani et al, 1989), and yielded a 508-base pair product. PCR products were not detected if RNA or reverse transcriptase was omitted from the reaction mixture.

\section{Cell Extraction}

Aliquots of $1 \times 10^{7}$ of BMMC or $5 \times 10^{5}$ PMC were suspended in $50 \mu$ l of a buffer solution containing $1 \%$ Nonidet P40 (Nacalai Tesque, Kyoto, Japan), $50 \mathrm{~mm}$ Tris- $\mathrm{HCl}$ (pH 8.0), $150 \mathrm{~mm} \mathrm{NaCl}, 1 \mathrm{~mm}$ EDTA, and $1 \mathrm{~mm}$ phenylmethylsulfonyl fluoride (PMSF). After a 30minute incubation on ice, cell suspensions were centrifuged at $15,000 \times g$ for 10 minutes at $4^{\circ} \mathrm{C}$. The soluble extract was mixed in SDS-PAGE sample buffer (60 mm Tris, pH 6.8, 2\% SDS, 10\% glycerin, $0.001 \%$ bromophenol blue (BPB), and 5\% 2-ME), and then boiled for 5 minutes. In preliminary experiments, cadherins were shown to be efficiently extracted by this method, although extraction of catenin molecules was unstable probably because of the degradation of catenins by proteinases in mast cells. Thus, for extraction of catenins, BMMC or PMC were pretreated with ice-cold $10 \%(\mathrm{v} / \mathrm{v})$ trifluoroacetic acid (Nacalai Tesque, Kyoto, Japan) in PBS for 30 minutes. Cell suspensions were then centrifuged at $15,000 \times g$ for 5 minutes, and the cell pellets were resuspended in 80 $\mu$ of urea extraction buffer (9 M urea, $2 \%$ Triton X-100, and 5\% 2-ME in distilled water). After sonication, an appropriate volume of $10 \%$ SDS was added and $\mathrm{pH}$ was optimized with $1 \mathrm{M}$ Tris. Extracts of the cells constitutively expressing E-cadherin (IEC-6, rat small intestine epithelial cell line; Riken Cell Bank, Tsukuba, Japan), N-cadherin (KPN-RT, human neuroblastoma cell line, a gift from Prof. T. Sugimoto, Miyazaki Medical College, Miyazaki, Japan) or catenins (HeLa and A431 cell line, Transduction Laboratories) were also prepared and used as positive controls.

\section{Immunoblotting}

Samples containing $30 \mu \mathrm{g}$ of proteins from BMMC or 30 to $80 \mu \mathrm{g}$ proteins from PMC were separated on $7.5 \%$ polyacrylamide gels and transferred onto Immobilon $\mathrm{P}$ membranes (Millipore Company, Bedford, Massachusetts) using a semidry transfer unit. Membranes were incubated with $3 \%$ nonfat dried milk in PBS containing $0.05 \%$ Tween-20 (PBS-Tween) for 1 hour, followed by incubation with antibodies specific for E-cadherin (clone 36), $\alpha$ - and $\beta$-catenin, or p120 at $4^{\circ} \mathrm{C}$ overnight. As negative controls, specific antibodies were omitted or isotype-matched nonspecific immunoglobulin was used. The membrane was washed with PBS-Tween and subsequently incubated with goat antimouse immunoglobulins conjugated with peroxidase labeled-dextran polymer. Chemiluminescence reagent (NEM Life Science Products, Boston, Massachusetts) was used to visualize the peroxidaselabeled protein bands according to the manufacturer's instructions.

\section{Immunoprecipitation}

BMMC were washed with HBSS and extracted with 50 $\mathrm{mm}$ Tris- $\mathrm{HCl}, \mathrm{pH}$ 8.0, containing 1\% NP-40, $150 \mathrm{~mm}$ $\mathrm{NaCl}, 1 \mathrm{~mm}$ EDTA, and $1 \mathrm{~mm}$ PMSF. After centrifugation at $15,000 \times g$ for 10 minutes, the supernatants were absorbed with Sepharose $4 \mathrm{~B}$ for 30 minutes and centrifuged at $1,200 \times g$ for 10 seconds. The preabsorbed extract was incubated with anti- $\beta$-catenin antibody, anti-E-cadherin antibody or isotype-matched control antibody (mouse lgG1 or lgG2a), or without antibody for 1 hour on ice, followed by addition of Sepharose 4B-conjugated with antimouse IgG, and incubation was continued for 30 minutes under gentle stirring. After centrifugation at $1,200 \times g$ for $10 \mathrm{sec}-$ onds, the Sepharose $4 \mathrm{~B}$ pellets were rinsed three times with extraction buffer and finally suspended in SDS-PAGE sample buffer and boiled for 5 minutes. The samples were centrifuged at $3,500 \times g$ for 10 minutes, separated by SDS-PAGE, and Western blotting was performed as described.

\section{Mast Cell Cultures to Determine Growth Inhibition by Anti-E-Cadherin Antibody or Decapeptides}

Intraepithelial mononuclear cells (IEMNC) from the mouse small intestine were prepared as described previously (Tegoshi et al, 1997). Freshly isolated IEMNC or BMMC, obtained 4 weeks after the start of culture, were subjected to clonal culture in methylcellulose. Aliquots of $1 \times 10^{6}$ IEMNC or $5 \times 10^{3}$ BMMC were mixed with $10 \mathrm{ml}$ of culture media containing $\alpha$-MEM, 0.9\% (v/v) methylcellulose, 25\% (v/v) FCS, $20 \%$ (v/v) PWM-SCM, $10^{-4}$ M 2-ME with ECCD-1, -2 or control antibodies, or with synthetic peptides, and aliquots of $200 \mu$ l were plated in 24 -well culture plates. Plates were incubated at $37^{\circ} \mathrm{C}$ in a humidified $5 \%$ $\mathrm{CO}_{2}$ atmosphere for 10 days. Numbers of colonies were counted under an inverted microscope.

To examine growth inhibition by anti-E-cadherin antibody in liquid cultures, aliquots of $3 \times 10^{4} \mathrm{BMMC}$ 
were incubated with ECCD-1, -2, or control antibodies in 96-well plates at $37^{\circ} \mathrm{C}$ in a humidified $5 \% \mathrm{CO}_{2}$ atmosphere for 5 days. Numbers of mast cells were determined using a hemocytometer. MTS colorimetric assay [3-(4,5-dimethylthiazol-2-yl)-5-(3-carboxymethoxyphenyl)2-(4-sulfophenyl)-2H-tetrazolium, inner salts] of numbers of viable cells was also carried out using a cell proliferation assay kit (CellTiter 96 AQueous; Promega, Madison, Wisconsin) according to the manufacturer's instructions.

\section{Cell Adhesion Assay}

The mouse teratocarcinoma cell-line F9 (Health Science Research Resources Bank, Osaka, Japan), which constitutively expresses E-cadherin (YoshidaNoro et al, 1984), was maintained in $\alpha$-MEM supplemented with 10\% FBS, $100 \mathrm{lU} / \mathrm{ml}$ penicillin, and 100 $\mu \mathrm{g} / \mathrm{ml}$ streptomycin. Monolayers of F9 cells were grown in flat-bottomed, collagen type, I-coated, 96well tissue culture plates (Becton Dickinson, Franklin Lakes, New Jersey). To label BMMC, $5 \mu$ l of BCECF-AM solution ( $5 \mathrm{mg} / \mathrm{ml}$ dissolved in DMSO) was added to $1 \mathrm{ml}$ suspension solution of $5 \times 10^{6}$ BMMC in $\alpha$-MEM supplemented with $1 \%$ FBS and incubated for 30 minutes at $37^{\circ} \mathrm{C}$. After washing with $\alpha$-MEM, $5 \times 10^{4}$ labeled BMMC were preincubated for 15 minutes at $37^{\circ} \mathrm{C}$ in $100 \mu \mathrm{l}$ of a medium consisting of $\alpha$-MEM and $10 \%$ FBS supplemented without or with mAbs or synthetic peptides, and added in quadruplicate to 96-well plates with F9 cell monolayer. After a 30-minute incubation at $37^{\circ} \mathrm{C}$, medium containing floating BMMC, which did not bind to the F9 cell monolayer, was aspirated using a 26-gauge needle, and wells were filled with $100 \mu$ l of PBS. Fluorescence intensity (FI) in each well was measured using a fluorescence plate reader (Millipore) with excitation at $485 \mathrm{~nm}$ and emission at $530 \mathrm{~nm}$. To plot a standard curve, various numbers of labeled BMMC were added to 96-well plates with F9 cell monolayers, and FI was directly measured without aspiration of floating cells: 1 to $6 \times 10^{4}$ labeled BMMC always produced approximate linearity of $\mathrm{FI}$. The number of bound BMMC in each well was determined in reference to the standard curve, and percentage of bound cells was determined. In another experiment, F9 monolayers were labeled with BCECF-AM and incubated with various doses of ECCD-1 or E-cadherin peptide 232-41. After culture medium was aspirated and replaced with PBS, FI was measured as described.

\section{Statistical Analysis}

Statistical analysis was performed by Student's $t$ test. Data are expressed as means \pm SD.

\section{References}

Aiba S, Nakagawa S, Ozawa H, and Tagami H (1995). Different expression of E-cadherin by two cutaneous gamma/delta $\mathrm{TcR}^{+} \mathrm{T}$-cell subsets, $\mathrm{V}$ gamma 5 - and $\mathrm{V}$ gamma $5^{+}$ gamma/delta TcR $^{+}$T cells. J Invest Dermatol 105:379-382.
Armeanu S, Buhring HJ, Reuss BM, Muller CA, and Klein G (1995). E-cadherin is functionally involved in the maturation of the erythroid lineage. J Cell Biol 131:243-249.

Bianchine PJ, Burd PR, and Metcalfe DD (1992). IL-3dependent mast cells attach to plate-bound vitronectin. Demonstration of augmented proliferation in response to signals transduced via cell surface vitronectin receptors. J Immunol 149:3665-3671.

Buhring HJ, Muller T, Herbst R, Cole S, Rappold I, Schuller W, Zhu X, Fritzsch U, Faul C, Armeanu S, Ullich A, Klein G, and Schmidt H (1996). The adhesion molecule E-cadherin and a surface antigen recognized by the antibody $9 \mathrm{C} 4$ are selectively expressed on erythroid cells of defined maturational stages. Leukemia 10:106-116.

Caux C, Vanbervliet B, Massacrier C, Dezutter-Dambuyant C, de Saint-Vis B, Jacquet C, Yoneda K, Imamura S, Schmitt D, and Banchereau J (1996). CD34+ hematopoietic progenitors from human cord blood differentiate along two independent dendritic cell pathways in response to GM-CSF+TNF alpha. J Exp Med 184:695-706.

Cepek KL, Shaw SK, Parker CM, Russell GJ, Morrow JS, Rimm DL, and Brenner MB (1994). Adhesion between epithelial cells and $T$ lymphocytes mediated by E-cadherin and the alpha E beta 7 integrin. Nature 372:190-193.

Ducharme LA and Weis JH (1992). Modulation of integrin expression during mast cell differentiation. Eur $\mathrm{J}$ Immunol 22:2603-2607.

Enerbäck L and Svensson I (1980). Isolation of rat peritoneal mast cells by centrifugation on density gradients of Percoll. $\mathrm{J}$ Immunol Methods 39:135-145.

Gilchrist M, MacDonald AJ, Neverova I, Ritchie B, and Befus $A D$ (1997). Optimization of the isolation and effective use of mRNA from rat mast cells. J Immunol Methods 201:207-214.

Gurish MF, Bell AF, Smith TJ, Ducharme LA, Wang RK, and Weis JH (1992). Expression of murine beta 7, alpha 4, and beta 1 integrin genes by rodent mast cells. J Immunol 149:1964-1972.

Hatta K and Takeichi M (1986). Expression of N-cadherin adhesion molecules associated with early morphogenetic events in chick development. Nature 320:447-449.

Karecla PI, Bowden SJ, Green SJ, and Kilshaw PJ (1995). Recognition of E-cadherin on epithelial cells by the mucosal T cell integrin alpha M290 beta 7 (alpha E beta 7). Eur $\mathrm{J}$ Immunol 25:852-856.

Kawamura KK, Tsutsui J, Suzuki ST, Kanzaki T, and Ozawa M (1998). N-cadherin expressed on malignant T cell lymphoma cells is functional, and promotes heterotypic adhesion between the lymphoma cells and mesenchymal cells expressing N-cadherin. J Invest Dermatol 112:62-66.

Miyatani S, Shimamura K, Hatta M, Nagafuchi A, Nose A, Matsunaga M, Hatta K, and Takeichi M (1989). Neural cadherin: Role in selective cell-cell adhesion. Science 245: 631-635.

Munro SB and Blaschuk OW (1996). A comprehensive survey of the cadherins expressed in the testes of fetal, immature, and adult mice utilizing the polymerase chain reaction. Biol Reprod 55:822-827.

Munro SB, Duclos AJ, Jackson AR, Baines MG, and Blaschuk OW (1996). Characterization of cadherins expressed by murine thymocytes. Cell Immunol 169:309-312. 
Nagafuchi A, Shirayoshi Y, Okazaki K, Yasuda K, and Takeichi M (1987). Transformation of cell adhesion properties by exogenously introduced E-cadherin cDNA. Nature 329:341343.

Nagafuchi A and Takeichi M (1988). Cell binding function of $\mathrm{E}$-cadherin is regulated by the cytoplasmic domain. EMBO $\mathrm{J}$ 7:3679-3684.

Okada M, Nawa Y, Horii Y, Kitamura T, and Arizono N (1997). Development of basophils in Mongolian gerbils: Formation of basophilic cell clusters in the bone marrow after Nippostrongylus brasiliensis infection. Lab Invest 76:89-97.

Ozawa M, Baribault H, and Kemler R (1989). The cytoplasmic domain of the cell adhesion molecule uvomorulin associates with three independent proteins structurally related in different species. EMBO J 8:1711-1717.

Palecanda A, Briskin MJ, and Issekutz TB (1997). Rat mast cell lines bind to the vascular cell adhesion molecule-1 (VCAM-1) and the mucosal addressin cell adhesion molecule-1 (MAdCAM-1). J Immunol 158:2904-2910.

Pece S, Chiariello M, Murga C, and Gutkind JS (1999). Activation of the protein kinase Akt/PKB by the formation of E-cadherin-mediated cell-cell junctions. Evidence for the association of phosphatidylinositol 3-kinase with the E-cadherin adhesion complex. J Biol Chem 274:1934719351.

Reynolds AB, Daniel J, McCrea PD, Wheelock MJ, Wu J, and Zhang Z (1994). Identification of a new catenin: The tyrosine kinase substrate p120cas associates with E-cadherin complexes. Mol Cell Biol 14:8333-8342.

Shibamoto S, Hayakawa M, Takeuchi K, Hori T, Miyazawa K, Kitamura N, Johnson KR, Wheelock MJ, Matsuyoshi N, Takeichi M, and Ito $F$ (1995). Association of p120, a tyrosine kinase substrate, with E-cadherin/catenin complexes. J Cell Biol 128:949-957.

Shimoyama Y, Nagafuchi A, Fujita S, Gotoh M, Takeichi M, Tsukita S, and Hirohashi S (1992). Cadherin dysfunction in a human cancer cell line: Possible involvement of loss of alpha-catenin expression in reduced cell-cell adhesiveness. Cancer Res 52:5770-5774.
Shirayoshi Y, Nose A, Iwasaki K, and Takeichi M (1986). $\mathrm{N}$-linked oligosaccharides are not involved in the function of a cell-cell binding glycoprotein E-cadherin. Cell Struct Funct 11:245-252.

Smith TJ, Ducharme LA, Shaw SK, Parker CM, Brenner MB, Kilshaw PJ, and Weis JH (1994). Murine M290 integrin expression modulated by mast cell activation. Immunity $1: 393-403$.

Takeichi M (1991). Cadherin cell adhesion receptors as a morphogenetic regulator. Science 251:1451-1455.

Takeichi M (1995). Morphogenetic roles of classic cadherins. Curr Opin Cell Biol 7:619-627.

Tang A, Amagai M, Granger LG, Stanley JR, and Udey MC (1993). Adhesion of epidermal Langerhans cells to keratinocytes mediated by E-cadherin. Nature 361:82-85.

Tegoshi T, Okada M, Nishida M, and Arizono N (1997). Early increase of gut intraepithelial mast cell precursors following Strongyloides venezuelensis infection in mice. Parasitology 114:181-187.

Thompson HL, Burbelo PD, and Metcalfe DD (1990). Regulation of adhesion of mouse bone marrow-derived mast cells to laminin. J Immunol 145:3425-3431.

Thompson HL, Burbelo PD, Yamada Y, Kleinman HK, and Metcalfe DD (1989). Mast cells chemotax to laminin with enhancement after IgE-mediated activation. J Immunol 143: 4188-4192.

Tsutsui J, Moriyama M, Arima N, Ohtsubo H, Tanaka H, and Ozawa M (1996). Expression of cadherin-catenin complexes in human leukemia cell lines. J Biochem Tokyo 120:10341039.

Yoshida-Noro C, Suzuki N, and Takeichi M (1984). Molecular nature of the calcium-dependent cell-cell adhesion system in mouse teratocarcinoma and embryonic cells studied with a monoclonal antibody. Dev Biol 101:19-27. 